\title{
Round Instrumentation for Aerospace Application
}

\author{
Srinivas Bachu ${ }^{1}$, B. Supriya ${ }^{2}$ \\ Guru Nanak Institutions Technical Campus \\ Hyderabad \\ Telangana \\ India \\ bachusrinivas@gmail.com
}

\begin{abstract}
Increase of science and technology lead to the development of variety of missiles. Generally, a missile consists of four system components targeting and/or missile guidance, flight system, engine and war head. In order to determine the effectiveness, yield and explosive capability of these components several tests had to be done. These tests can yield their information on how they work, as well as how missile behave under various conditions. Tests like Pressure Position Test (PPT), Null Position Test (NPT), and Vectoring Tests are carried on each flex nozzle system of a missile to verify the performance of flex seal using electro hydraulic actuators, mirror image sensor and electronic controller. These tests are done for acceptance of flex nozzle control system in the missile. During the test command, pitch, average, main voltages are recorded using DAC. The flex nozzle system is integrated to pressure chamber in horizontal condition and actuators. Then the PPT, NPT and Vectoring Tests are performed using electro hydraulic actuators. In the process mentioned above, it is evident that every missile and its subsystems should be tested in order to get approved. The testing part is done by measuring certain quantities such as stress, strain, pressure, load and temperature. These quantities are compared with the standard results. Measuring of any quantity requires the help of the instrumentation. So instrumentation plays a vital role in the testing of missile system. Without the helping of this, launching of the missile is next to impossible.
\end{abstract}

Keywords: Ground Instrumentation, Pressure Position Test, Null Position Test, Vectoring Tests

Received: 19 November 2017, Revised 6 January 2018, Accepted 24 January 2018

DOI: $10.6025 / \mathrm{jes} / 2018 / 8 / 2 / 45-56$

(C) 2018 DLINE. All Rights Reserved

\section{Introduction}

Instrumentation is a technology of measurement of which serves not only science but all the branches of engineering, medicine and almost every endeavor. The knowledge of any parameter largely depends on the measurement. The in depth knowledge of any parameter can be easily understood by use of measurement, and further modifications can also be obtained. Measuring is basically used to monitor a process or operation, or as well as the controlling process. For example, barometer, anemometer are used to measure the environment conditions. Similarly, water, gas and electric meters are used to keep the track of quantity of the commodity used and also special monitoring equipment is used in hospitals. Whatever may be the nature of application, intelligent selection and used of measuring equipment depends on broad knowledge of what is available and how the performance of equipment renders itself for the job to be performed. But there are basic measurement techniques and devices that are useful and will continued to be widely used also. There is always a need for improvement and development of the new equipment to solve measurement problems $[1,2]$.

Journal of Electronic Systems Volume 8 Number 2 June 2018 
The major encountered with any measuring instrument is the error. Therefore it is obviously necessary to select the appropriate measuring instrument and measurement method which minimizes the error. To avoid the errors in any experimental work, execution, careful planning and evaluation of the experiment are essential.

The basic concern of any measurement is that measuring instrument should not affect the quantity being measured; in practice, this non interference principle is never strictly obeyed. Null measurement minimizes these interference effects.

\section{The Game Scripting Problem Domain}

Basically a missile has four major components as shown in Figure 1. They are: Rocket motor, Propellant (fuel), Propellant (oxidizer), Control guidance and Payload. The rocket motor section consists of nozzle which determines the direction of the missile. The propellant (fuel) consists of the solid propellant which fuels the missile. The propellant (oxidizer) is where the solid fuel combusts under great pressure and converts into gases such as $\mathrm{CO} 2, \mathrm{CH} 4$ etc. Control \& guidance section makes that the missile follows the trajectory $[2,3]$. Pay load is the part of the missile is finally left and follows the target.

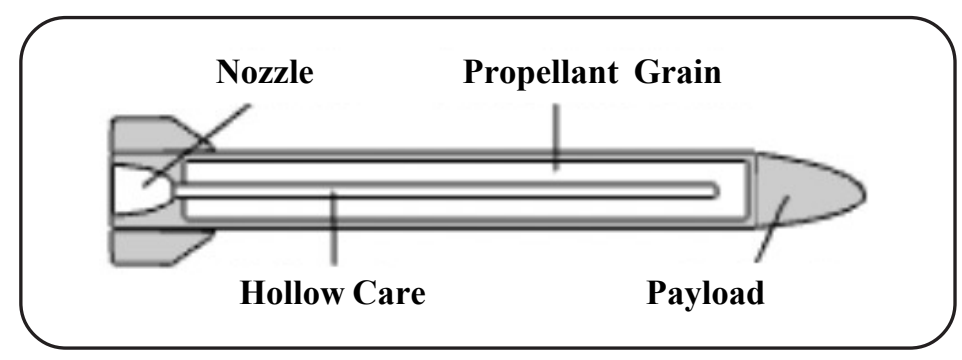

Figure 1. Basic Components of Missile

\subsection{Main Components of Solid Rocket Motor}

The Figure 2 gives a descriptive vision of a solid rocket motor. It is designed to ensure the combustion under pressure of the propellant grain it contains. The resulting gases are expanded through the nozzle, whose function is to convert this pressure in to supersonic exhaust. As a rule such a rocket motor has five major components: case, propellant grain, thermal insulation, ignition system and nozzle.

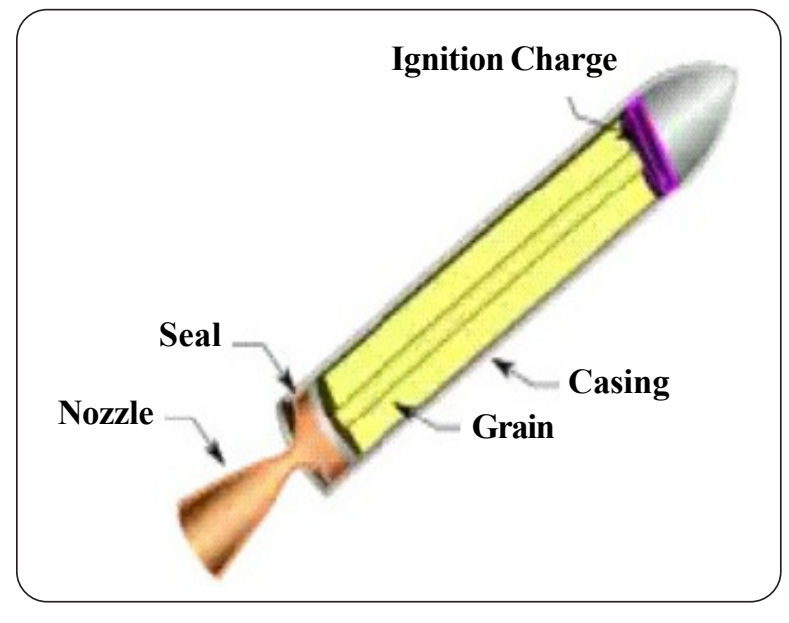

Figure 2(a). Solid Rocket Motor

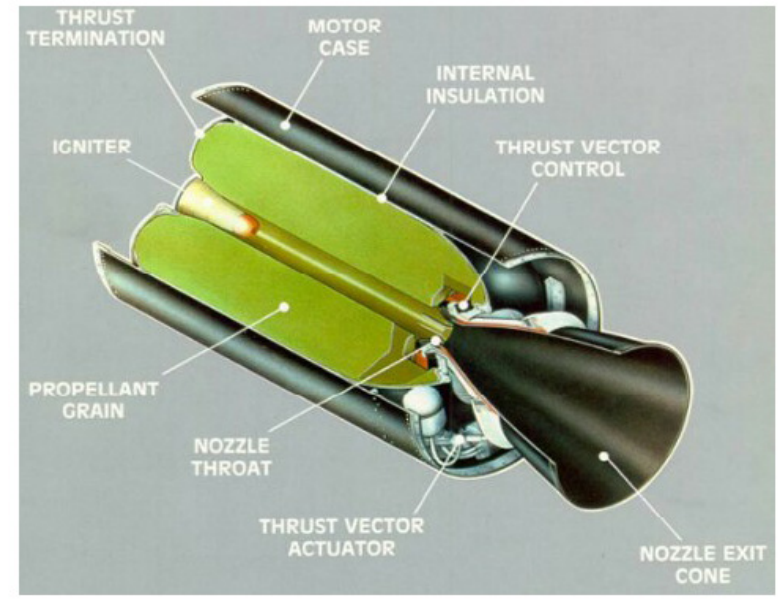

Figure 2(b). Components of Rocket Motor

\section{The Case}

Made either from metal (high resistance steels) or from composite materials by filament winding (glass, kelvar, carbon), the case must be capable of withstanding the internal pressure resulting from motor operation, approximately 3-25M pa. 


\section{Propellant Grain}

Two main configurations freestanding grain and case-bonded grain-with various central port geometrics are used to fulfill the required performance objectives. Freestanding grains are contained in a cylindrical plastic cartridge (PVC, etc). They are secured inside the case by various support elements such as wedges, springs or grids. Case bonded grains are obtained by casing the propellant, before polymerization has occurred, directly into a case already provided with thermal insulation.

The combination temperature of propellant grains, ranging approximately 1500 to $3000 \mathrm{k}$ requires the protection of the inside surface of the case $[1,2]$. The design of internal insulation involves following steps.

-Analysis of the Internal Environment: The nature of propellant gases, internal dynamics etc.

- Selection of Material: Reduced scale tests designed to assess specimens in conditions simulating firing are performed.

- Determination if thickness in various areas of the case necessary to withstand the heat.

- Determination of the dimensions and thickness needed to withstand mechanical strains on the case and propellant grain.

\section{The Ignition System}

The ignition system brings the necessary to the surface of the propellant to start burning is shown in Figure 3 . There are three stages:

- Initiator: A pyrotechnic element designed to transform an ignition system such as shock. Electrical impulse or light into the steady burning of a pyrotechnic substance.

- Booster Charge: A charge, power, pellets or propellant micro rocket that transmits flame between the primer and main grain.

- Main Charge: A charge, powder, pellets or propellant rocket that ignites the propellant grain.

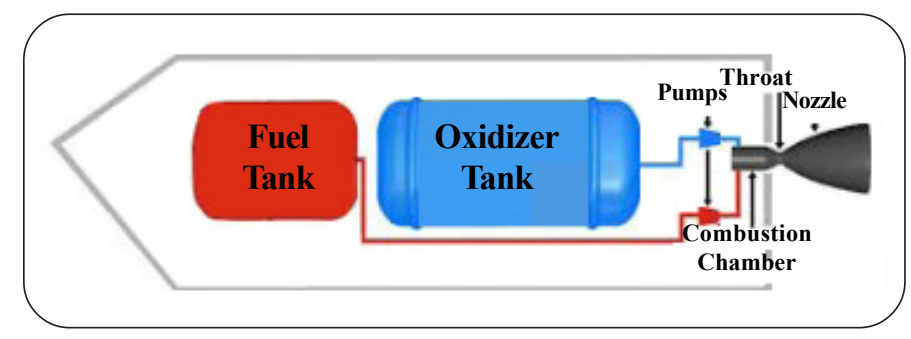

Figure 3. Missile Ignition System

\section{The Nozzle}

A nozzle may be defined as a passage of varying cross section, through which heat energy is converted into kinetic energy. Its major function is to give thrust into aerospace vehicle. Nozzle plays a major role in providing the necessary thrust to the rocket. The gases expand through the nozzle, whose function is to convert this pressure into supersonic exhaust. The general shape of the nozzle shown in Figure 4 is called nozzle profile, includes three major parts.

The convert nozzle can accelerate the missile only to subsonic speeds and if supersonic speeds (Mach number>1) are to be achieved a setup is needed shown as above called convergent-divergent nozzle. The convergent zone of the nozzle, channels the flow of propellant combustion gases. The dimensions of the throat section, determines the operating point of the rocket motor. The exit cone of the nozzle, which increases the exhaust velocity of the gases in the expansion phase, consequently improving the propulsive effect.

Currently, the shape and complexity of the nozzle depend on the expected level of performance and on the field of application of rocket motor (space, ballistic missile and tactile missile).

The design of nozzle requires knowledge of following parameters. 


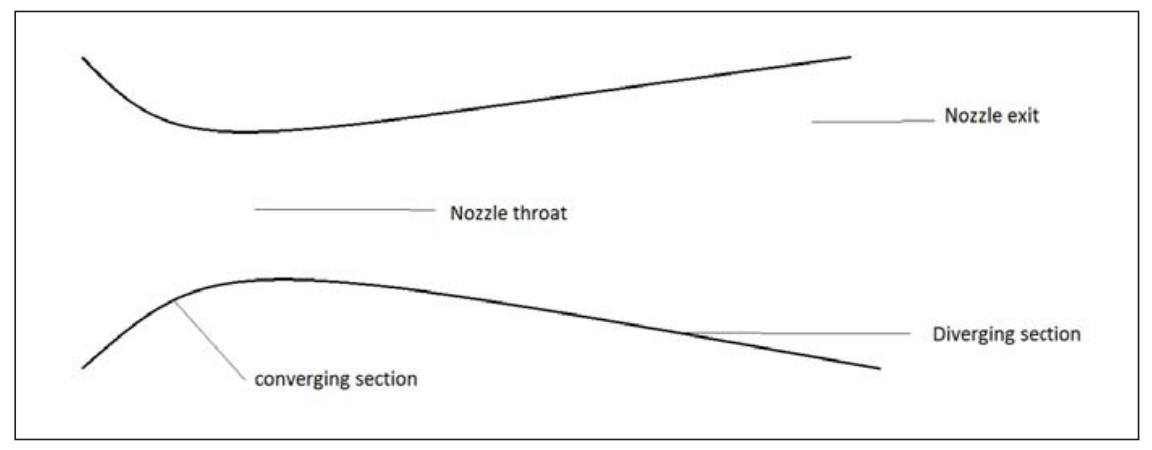

Figure 4. Structure of the Nozzle

- Internal operating pressure of the motor, which affects the structural integrity of nozzle and ablation of the thermal materials.

- Burning time, often negligible for small rocket motors (a few seconds) but in the case of +large rockets motors (measured by minute) an essential factor in determination of the thickness required to withstand the thermal transfer.

- Throat diameter, which will determine the operating pressure.

- Type of propellant used, the gases and propellant's burning temperature determine selection of thermal material.

- Space available, often a function of equipment necessary for the guidance of the missile for example, the nozzle's located at the end of the blast tube on some tactile engines.

- Expansion ratio (exit cone area vs. nozzle throat area, i.e. $E=A s / A t$ ) must allow maximum efficiency. Because space is usually limited on ballistic missile the concept of extendible nozzle exit cone (during flight) permits an increase in the ratio during the operation.

\subsection{Need for Nozzle Testing}

Nozzle is the vital component of the missile guiding system. The direction in which it moves determines the direction of the missile trajectory. When the missile is intended to move towards right, the nozzle has to move towards left and vice versa. Hence the nozzle moves in clock wise direction causes an equal inclination of the missile trajectory in the counter clock wise direction.

Missile is usually fired from a canister within which the missile is enclosed. When the missile is ignited from the fuel placed in the lower part of the canister, the liquid fuel converts into gas under great pressure which in turn provides the required thrust to the nozzle. This would generate high pressure and temperature which act as stress on the nozzle causing the nozzle to strain. Hence it is necessary that the nozzle be properly tested to verify whether the nozzle can with stand the specified amounts of stress $[5,6]$.

\section{Testing of Flex Seals}

This chapter brings out details of various acceptance tests such as Proof pressure test (PPT), Null position test (NPT) and Vectoring tests with ejection loads simulation and pull tests. The design approach towards the test setups and simulation of load conditions is brought out.

\subsection{Loading Conditions}

The major loading conditions during flex seal operation are

- Pressure / ejection load.

- Vectoring loads

- Thermal loads.

\section{The Pressure Load / Ejection Load}


The solid rocket motor during operation has a MEOP and Correspondingly the distribution on the convergent-divergent nozzle contour. The pressure integral over the convergent-divergent contour is known as ejection load, which has to be taken by the flex seal reinforcements.

\section{Vectoring Loads}

The thrust vectoring requires the nozzle to be vectored in perpendicular planes resulting in shear loads in the elastomeric of the flex seal. The seal stiffness in shear has to be minimum to reduce the actuator load and its associated design. The requirement of

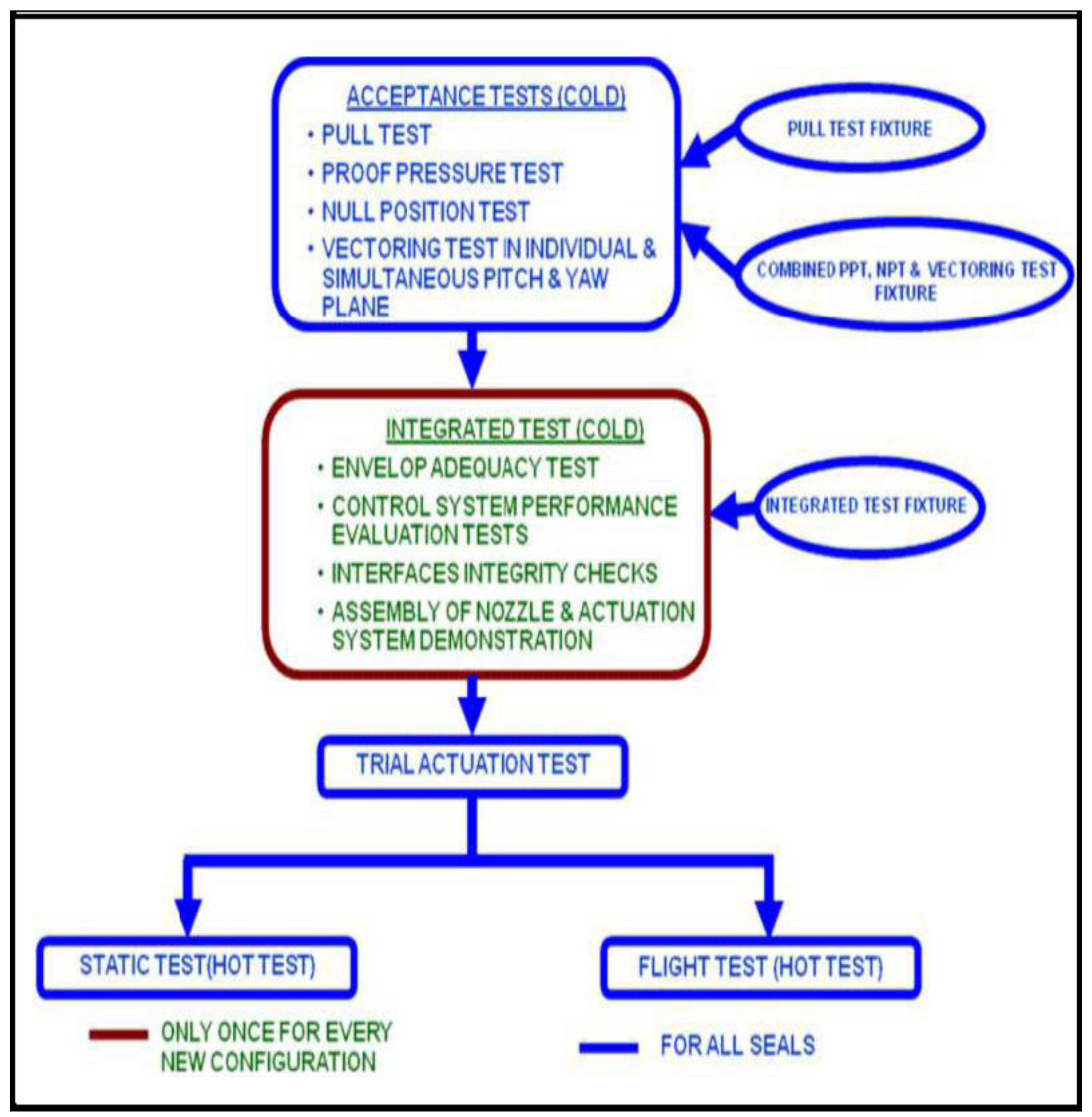

Figure 5. Developmental test plan for flex seal tests 
actuator force is inversely proportional to the pressure.

\section{Thermal Loads}

The flex seal is usually designed with thermal protection system, which protects the seal from hot gases from combustion chamber, but the ambient soaking conditions of the solid rocket motor with the flex nozzle system during long storage are imposed [4-6].

\section{Developmental Test Plan for Flex Seal}

For reliable functioning of flex seal systems during flight of rocket motors, the seal has to be qualified under all the above loading / environmental conditions. A developmental test plan as shown in Figure 5 has been evolved.

\subsection{Acceptance Tests}

Objectives of acceptance tests are to evaluate the, Pressure sealing capability, Vectoring capability under pressure load, Spring stiffness, Axial deflection, Structural integrity of the seal and Hysteresis characteristics.

\section{Proof Pressure Test}

This test is done to simulate motor maximum expected operating pressure up to proof pressure levels and check the pressure sealing capability. The MEOP for all the six configurations are given in Table 1. The chamber will be pressurized to the proof pressure in steps of 1.0 MPa with a hold time of 3 minutes at proof pressure and return back to zero pressure in same steps. At each pressure step, strains on shims, seal compression and pressure will be recorded in the data acquisition system.

\section{Null Position Test}

This test is done to simulate ejection load and measure the behaviour of flex seal due to asymmetry in geometry. In this test, the pressure is increased from zero to a pressure, which creates equivalent ejection load in steps of $1.0 \mathrm{MPa}$ with a hold time of 3 minutes at maximum pressure. Apart from this, the readings at $0.5 \mathrm{MPa}$ and motor average pressure will also be recorded. Seal compression, the force required to correct the deflection due to asymmetry, pressure and strains on the shims are measured during each load step. The pivot point shift is measured by placing four LVDT's radically on the simulated divergent nearest to the pivot point. At every pressure step the shift is recorded after null correction and the maximum is reported. The calculated pressures for all the six configurations are given in Table 1.

\section{Vectoring Tests}

These tests are done to simulate angular deflection of flex seal with ejection load to characterize seal torque / Actuator force requirement and Actuator stroke requirements. The flex seal is vectored from $00-$ maximum angle -00 - negative maximum angle -00 in steps in one degree. Separate tests are done in individual pitch, yaw and in simultaneous planes. Vectoring tests are done at three pressures for configuration-D namely $0.5 \mathrm{MPa}, 4.02$ and 5.3 MPa to map the characteristics at lower, average and upper bound of rocket motor operations. Similar test have been done for other configurations with vectoring angles given in Table 1. The actuator force, stroke, deflection angle, pressure and strains on shims are measured at every load step.

\begin{tabular}{|l|l|l|l|l|l|l|}
\hline Test & Conf. A & Conf. B & Conf. C & Conf. D & Conf. E & Conf. F \\
\hline PPT(MPa) & 6.47 & 5.93 & 6.47 & 7.55 & 8.62 & 6.47 \\
\hline Proof EjectionLoad (kN) & 3451 & 809 & 809 & 2157 & 1320 & 517 \\
\hline NPT (MPa) & 4.47 & 4.70 & 4.35 & 5.3 & 6.42 & 4.9 \\
\hline Actuation Angle (Degree) & $\pm 5^{\circ}$ & $\pm 4^{\circ}$ & $\pm 4^{\circ}$ & $\pm 4^{\circ}$ & $\pm 3^{\circ}$ & $\pm 2^{\circ}$ \\
\hline
\end{tabular}

Table 1. Proof load levels for flex seal testing

\section{Instrumentation Plan for Acceptance Tests}

The flex seal is bonded with strain gauges on the inner diameter as per the plan shown in Figure 2. Table 2 presents the instrumentation plan for acceptance tests. 


\begin{tabular}{|l|l|l|l|l|l|}
\hline SLNO. & Parameters & $\begin{array}{c}\text { No. of } \\
\text { Channels }\end{array}$ & Location & Instrument Type/ Range & Applicable for \\
\hline 1 & Chamber pressure & 2 & Test fixture & $\begin{array}{l}\text { Pressure Transducer } \\
(0-100 \text { Mpa })\end{array}$ & All the tests \\
\hline 2 & Axial compression & 4 & Test fixture & LVDT $(0-20 \mathrm{~mm})$ & All the tests \\
\hline 3 & Angular deflection & 2 & $0-180 \& 90-270$ planes & Inclinometer(14) & Actuation tests \\
\hline 4 & Actuator load & 4 & Actuator Assy. & Load Cell $(0-15000 \mathrm{~kg}-\mathrm{f})$ & Actuation tests \\
\hline 5 & Actuator stroke & 2 & Actuator & Wire type LVDT $(100 \mathrm{~mm})$ & Actuation tests \\
\hline 6 & $\begin{array}{l}\text { Strains on flex seal sub } \\
\text { Assy. }\end{array}$ & 56 & $\begin{array}{l}4 \text { on each shim/Aft } \\
\text { End ring and } 24 \text { on } \\
\text { throat Housing }\end{array}$ & Strain gauge $(0-7000)$ & All Tests \\
\hline
\end{tabular}

Table 2. Instrumentation Plan for Acceptance Tests

\subsection{Integrated Test}

The main objectives of the integrated test are as follows:

- Evaluation of control system performance at different pressures with MI simulated flex nozzle simulating the interfaces.

- To evaluate the performance of flex seal sub assembly in conjunction with control system.

- To evaluate the structural integrity of interfaces and actuator attach points at different pressures and actuation conditions.

- To confirm the adequacy of envelope between fixed and movable parts during actuation.

\subsection{Trial Actuation Tests}

For every flex nozzle assembled to the solid rocket motor, before it is either static or flight tested, the nozzle is assembled to a simulated motor and pressurized to a level just to eliminate tensile loading on flex seal (usually $0.2 \mathrm{MPa}$ ) and a predefined duty cycle in both pitch and yaw planes are given to ascertain the integrated performance of controller and nozzle.

\subsection{Static Tests / Hot Tests}

To access the expected performance of flex seal with designed thermal protection system, hot test of solid rocket motor with flex nozzle system is carried out.

\subsection{Flight Tests}

To finally validate the performance of flex seal with control system in the actual operating conditions along with associated solid rocket motor components, flight tests are carried out.

\section{Test Setups for Acceptance Tests}

The test set-ups were designed for 6 different seal configurations with modular construction to carryout PPT, NPT and Vectoring tests with adaptations for each seal in single basic set up. Structural steel was used for the design of fixtures with cost, availability and fabrication considerations. The simulation of pressure is done with water instead of air to alleviate the safety problems while handling pneumatics on a day-to-day basis. The seal surfaces have been protected with an adeprine coating for the test purposes and subsequently peeled off.

The pressure chamber has been designed to 1.25 times the MEOP with minimum factor of safety of 2 . The top plate is designed to simulate the interfaces of intermediate dome with flex seal. It has suitable provisions to simulate the required actuator hinge points. In two of the cases, it was not possible to simulate the actuator mounting points with structural steel due to stiffness and

$$
\text { Journal of Electronic Systems Volume } 8 \text { Number } 2 \text { June } 2018
$$


space considerations and hence high strength materials like AFNOR 15CDV6 steel having ultimate tensile strength of 980 MPA were used.

The test configuration of flex seal with throat housing doesn't have throat insert and convergent but throat housing opening has to be closed for simulating pressure. Due to the presence of closure while simulating proof pressure on the seal, the loading on the seal is higher than computed by integral of pressure distribution over the convergent-divergent contour. Hence a relieving piston has been designed to relieve the extra load on the seal. One of the challenges was to design a relieving piston with approximate diameter of $400 \mathrm{~mm}$ with proper sealing under dynamic conditions. Proper seals selection, stringent control on machining tolerances between piston and housing has resulted in perfect sealing with mobility to piston while the flex seal gets compressed under pressure.

The vectoring set up consists of support frame / dummy divergent in addition to PPT components except spacer. The frame has been designed to take the actuator loads to deflect the seal to required angle during test. The double acting hydraulic actuators were designed for maximum vectoring load with minimum factor of safety of 2 .

\begin{tabular}{|c|c|c|c|c|c|}
\hline & $\begin{array}{l}\text { R2T } \\
\text { Shim 3 }\end{array}$ & $\begin{array}{l}\text { R1R } \\
\text { Shim } 3\end{array}$ & $\begin{array}{l}\text { R2B } \\
\text { Shim } 3\end{array}$ & $\begin{array}{l}\text { R1L } \\
\text { Shim } 3\end{array}$ & \\
\hline \multicolumn{2}{|c|}{ Pressure } & & & & Max deflection \\
\hline KSC & $\mu \mathrm{e}$ & $\mu \mathrm{e}$ & $\mu \mathrm{e}$ & $\mu \mathrm{e}$ & \\
\hline 0 & 0 & 0 & 0 & 0 & 0 \\
\hline 5 & -151.2 & -195.9 & -205.4 & -143.1 & -173.9 \\
\hline 10 & -285.4 & -337.6 & -345.1 & -271.9 & -310 \\
\hline 20 & -542.4 & -570.9 & -576.3 & -518.7 & -552.075 \\
\hline 30 & -784.4 & -789.2 & -793.9 & -755.3 & -780.7 \\
\hline 40 & -1025.8 & -1010.2 & -1012.9 & -989.9 & -1009.7 \\
\hline 50 & -1259 & -1228.5 & -1228.5 & -1215.7 & -1232.925 \\
\hline 60 & -1499.7 & -1455 & -1456.3 & -1449.6 & -1465.15 \\
\hline 70 & -1736.4 & -1682.1 & -1683.5 & -1680.8 & -1695.7 \\
\hline 70 & -1825.9 & -1781.8 & -1789.9 & -1764.8 & -1790.6 \\
\hline 60 & -1611.6 & -1580.4 & -1589.9 & -1554 & -1583.975 \\
\hline 50 & -1396 & -1383.1 & -1391.3 & -1344.5 & -1378.725 \\
\hline 40 & -1167.5 & -1177 & -1187.2 & -1123.4 & -1163.775 \\
\hline 30 & -941.7 & -973.6 & -983.8 & -901.7 & -950.2 \\
\hline 20 & -697.7 & -752.6 & -762.8 & -663.1 & -719.05 \\
\hline 10 & -453.6 & -513.2 & -526.8 & -424.4 & -479.5 \\
\hline 5 & -311.9 & -340.4 & -363.4 & -297 & -328.175 \\
\hline 0 & -114.6 & -87.5 & -111.2 & -111.9 & -106.3 \\
\hline
\end{tabular}

\begin{tabular}{|l|l|}
\hline Max Strain & 0 \\
\hline Min Strain & -1825.9 \\
\hline
\end{tabular}

Table 3.Table for shim 1 


\section{Results and Discussion}

\subsection{Results of Proof Pressure Test}

The results of the proof pressure test for shim 1 is shown in Table 3, for shim 2 are shown in Table 4 and also for the shim 3 are shown in Table 5.

During proof pressure test the maximum and minimum strain recorded for shim, shim 2 and shim 3 are $0,-1825.9 ; 0,-2107.2$ and 0 , -2171.6 on AER (70ksc).

\begin{tabular}{|l|l|}
\hline Max Strain & 0 \\
\hline Min Strain & -2107.2 \\
\hline
\end{tabular}

\begin{tabular}{|l|l|l|l|l|l|}
\hline \multicolumn{2}{|l|}{} & $\begin{array}{l}\text { R2T } \\
\text { Shim 3 }\end{array}$ & $\begin{array}{l}\text { R1R } \\
\text { Shim 3 }\end{array}$ & $\begin{array}{l}\text { R2B } \\
\text { Shim 3 }\end{array}$ & $\begin{array}{l}\text { R1L } \\
\text { Shim 3 }\end{array}$ \\
\hline \multicolumn{2}{|l|}{ Pressure } & & & & Max deflection \\
\hline KSC & $\mu \mathrm{e}$ & $\mu \mathrm{e}$ & $\mu \mathrm{e}$ & $\mu \mathrm{e}$ & \\
\hline 0 & 0 & 0 & 0 & 0 & 0 \\
\hline 5 & -162 & -175.6 & -187.8 & -158 & -170.85 \\
\hline 10 & -315.9 & -345.1 & -352.6 & -309.2 & -330.7 \\
\hline 20 & -607.5 & -651.6 & -652.9 & -601.4 & -628.35 \\
\hline 30 & -884.1 & -942.4 & -937 & -877.3 & -910.2 \\
\hline 40 & -1156 & -1230.6 & -1217.7 & -1146.5 & -1187.7 \\
\hline 50 & -1413 & -1505.8 & -1488.2 & -1402.1 & -1452.275 \\
\hline 60 & -1669.2 & -1780.4 & -1758.7 & -1657 & -1716.325 \\
\hline 70 & -1920.8 & -2051 & -2026.5 & -1908.6 & -1976.725 \\
\hline 70 & -1951.3 & -2107.2 & -2088.9 & -1944.5 & -2022.975 \\
\hline 60 & -1707.2 & -1848.2 & -1836 & -1703.1 & -1773.625 \\
\hline 50 & -1462.4 & -1589.2 & -1580.4 & -1458.4 & -1522.6 \\
\hline 40 & -1202.1 & -1312.6 & -1304.5 & -1198.7 & -1254.475 \\
\hline 30 & -943.8 & -1036 & -1024.5 & -935 & -984.825 \\
\hline 20 & -661.7 & -737 & -723.4 & -648.2 & -692.575 \\
\hline 10 & -373.6 & -423.8 & -417 & -358.7 & -393.275 \\
\hline 5 & -217.6 & -241.4 & -242.7 & -206.1 & -226.95 \\
\hline 0 & -38.6 & -38.6 & -39.3 & -33.2 & -37.425 \\
\hline
\end{tabular}

Table 4. Table for shim 2

\section{Conclusion}

During proof pressure test the minimum strain recorded for shim 1 is -1825.9 , shim 2 is -2107.2 , shim 3 is -2171.6 on AER (70ksc). The strain and compression levels for the tests meet the specification given for the flex seal. The results are in the permitted range. The strains that are obtained are in specified range. Displacement in LVDTs did not exceed $-10 \mathrm{~mm}$ and $+10 \mathrm{~mm}$. Maximum load on load cells didn't exceed $490 \mathrm{kgs}$. The seal that is manufactured is approved which can be used further in launching of rocket. We can also mould the equipment to the required applications. 


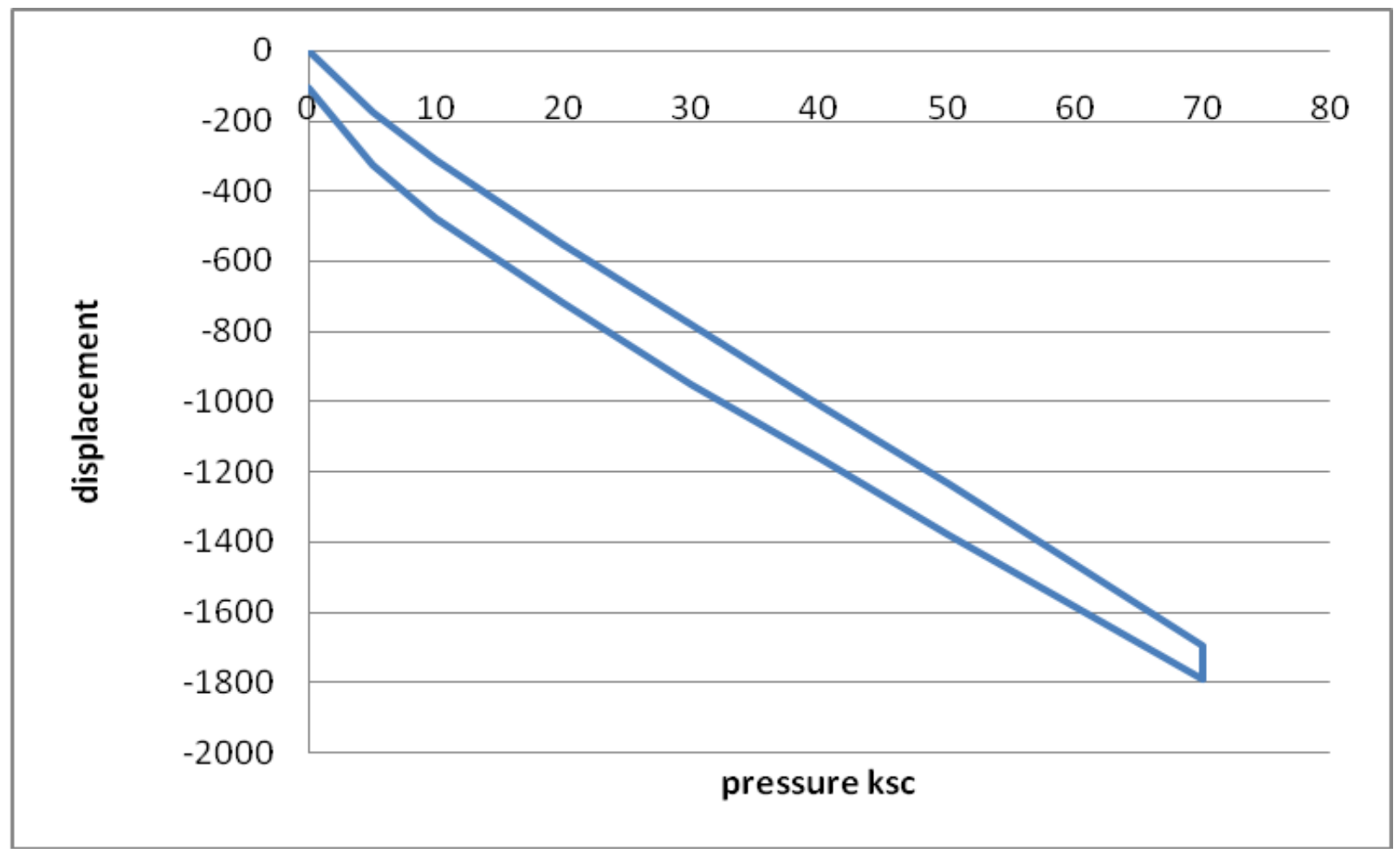

Figure 7. Plot for shim 1 table

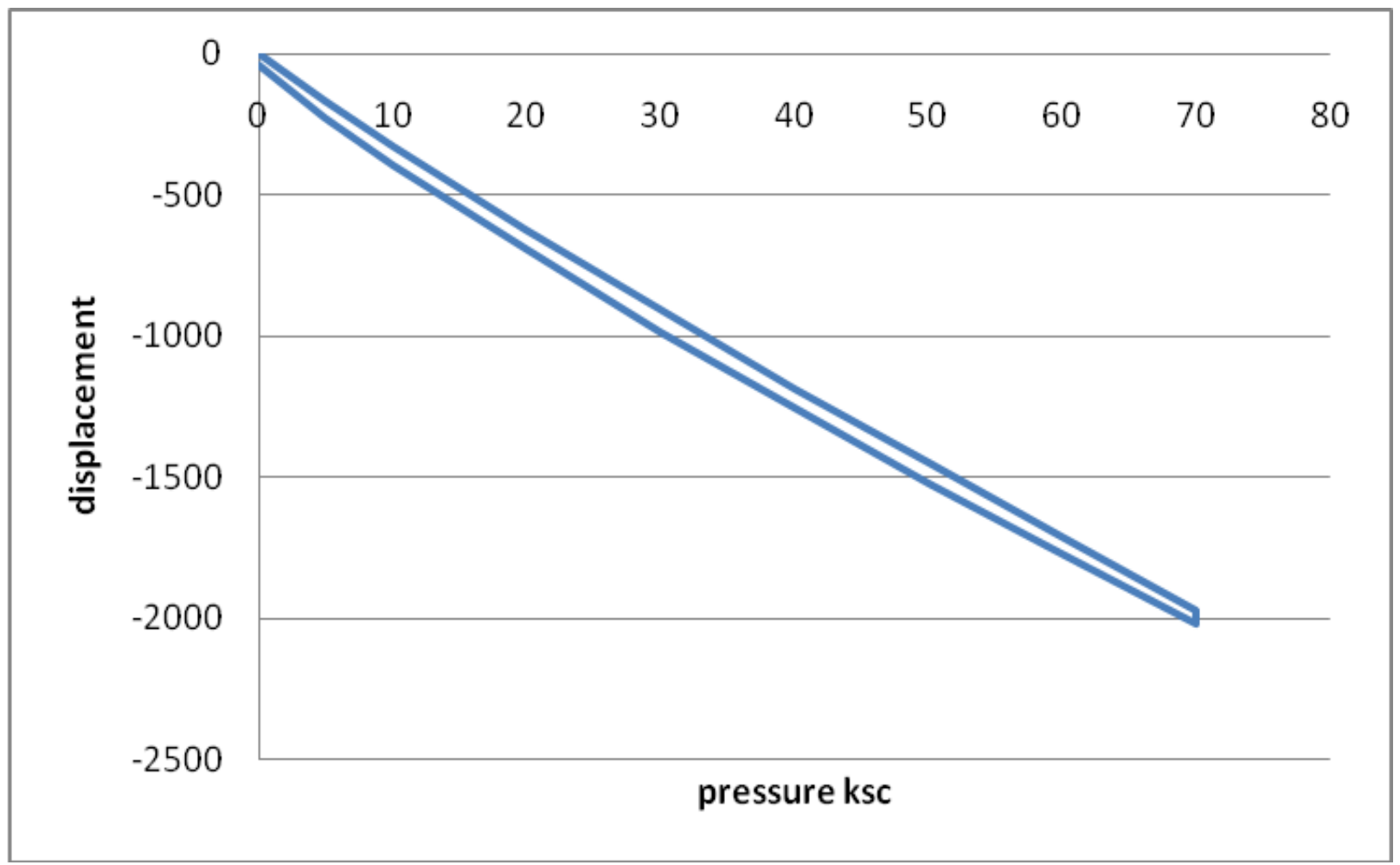

Figure 8. Plot for shim 2 table 


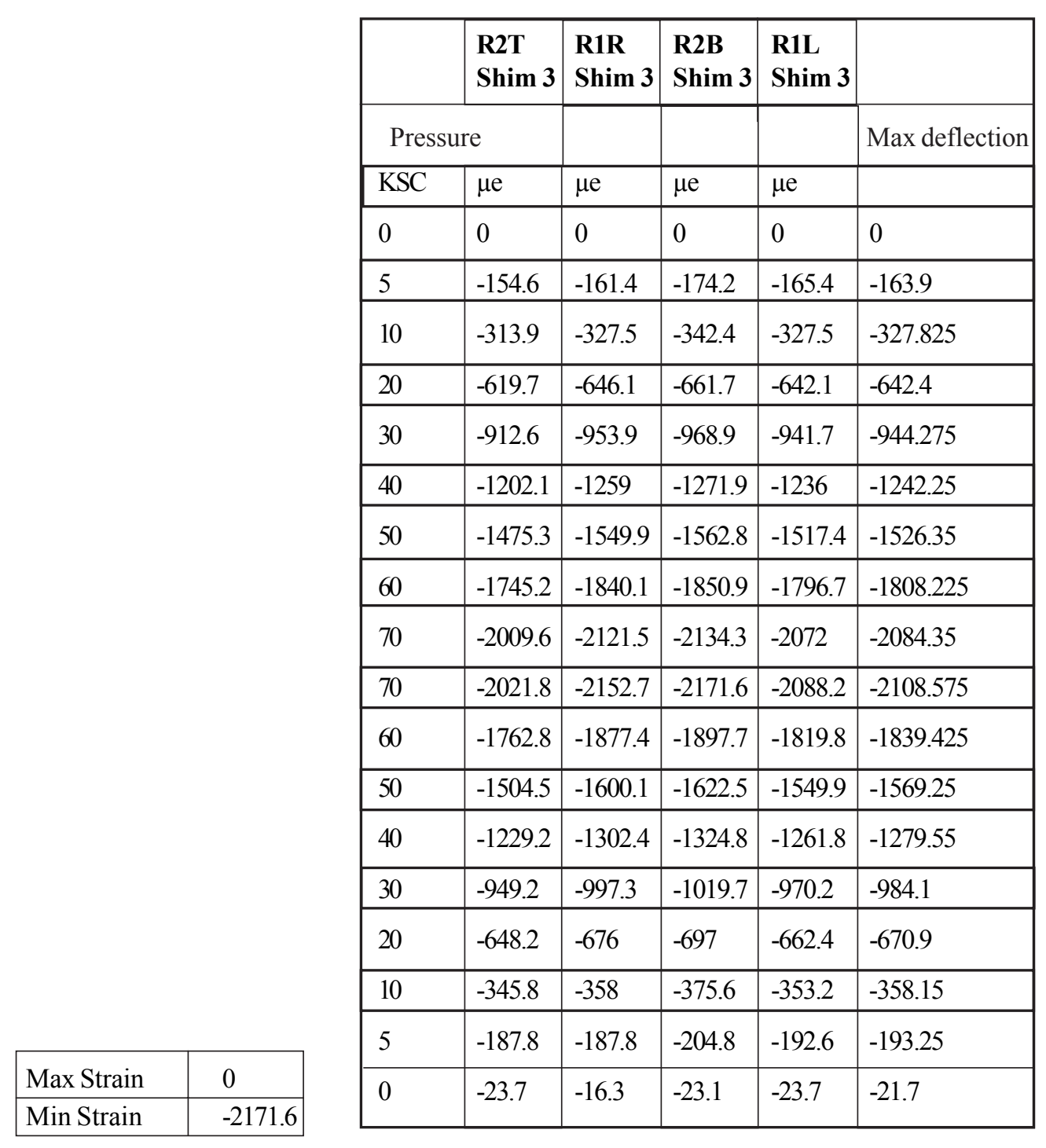

Table 4. Table for shim 3

Pressure vs displacement graphs for different shim are shown in Figure 7, Figure 8 and Figure 9.

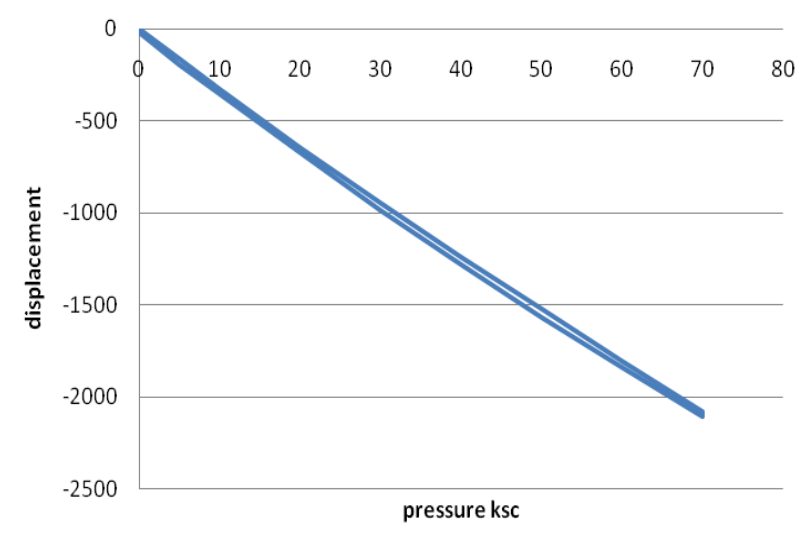

Figure 9. Plot for shim 3 table 
Strain measurement can be made using rosette strain gauge instead of linear strain gauge for better measurement of strains. If changes are made in the manufacturing of seal such that it can withstand higher pressures then, this can be used for high pressure applications. NCDT can be used instead of LVDT for higher displacement applications.

In this paper the results are manually noted and then the decision is made whether the flex seal is faulty or not, instead of doing manually we can design a software based application which can automatically detect the faulty values and automatically record them in a document. This software can be designed such that it can automatically decide whether the nozzle can be approved or not.

\section{References}

[1] Holden, M. S. (1991). Large Energy National Shock Tunnel (LENS) Description and Capabilities.

[2] Harvey, J., Bergman, R. C., and Holden, M. S. (1989). An Experimental Study of Hypersonic Turbulence on a Sharp Cone, AIAA-89-1866, AIAA 20th Fluid Dynamics, Plasma Dynamics and Lasers Conference.

[3] Karaguleff, C., Craig, J., Parker, R., Navaz, H.K. (1992). Design Considerations for an Infrared Camera System for Aero-Optical Window Evaluation, AIAA-92-2821, AIAA SDIO Interceptor Technology Conference.

[4] Indian Space Research Organization, Handbook of ISRO Test Facilities, ISRO-HQ-SP-63-92

[5] Hughes Aircraft Co. (1989). Radar Readiness Technologies.

[6] TRW. (1989). Radar Readiness Technologies, 1989. 